\title{
Overcoming Inadvertent Barriers to Entry in Large Infrastructure Projects
}

Peter Livesey, (University of Technology Sydney, Australia)

Justin Bold, (Bold Consulting Pty Ltd, Australia)

\begin{abstract}
The history behind the award of Brisbane City Council's Legacy Way project is discussed. The discussion focus on the possible impact of cognitive bias in the Expression of Interest (EOI) process together with the steps that were taken during the EOI development and evaluation phase to reduce the impact that this may have had on the selection of Contractors from their EOI submissions. The paper concludes that Cognitive Bias may have created a greater barrier to entry to Contractors attempting to enter the Australian PPP market than has been previously realised and makes suggestions as to how this effect could be minimised in the future.
\end{abstract}

Keywords: PPP, Infrastructure Projects, Barriers to Entry, Cognitive Bias

\section{Introduction}

Australian Government agencies and their state and local counterparts have been courting international construction companies for several years. The government has stated its desire to improve the efficiency of major infrastructure procurement (particularly PPPs) for the sake of securing the best possible value for money. To international contractors seeking to deploy highly skilled, highly experienced resources in new jurisdictions the government's intent is attractive, and with such capable resources on the prowl it's no wonder the Australian Government continues to entice.

Despite continued effort of both the Australian government and international contractors, very few projects in the civil infrastructure domain have been awarded to (or won by) international contractors. There have been numerous discussions and reports conducted with key stakeholders in an attempt to address this issue and unlock the potential of foreign involvement in major infrastructure projects. Interestingly, the conclusions from much of the discussion and debate have been remarkably similar.

A recent KPMG report (KPMG 2010) on behalf of Infrastructure Australia (IA) provides a good summary and concludes that most Participants (both private and public sector) felt that there was good competition within the Australian market, however factors identified as deterrent for both Australian and international competitors were:

- The unknown pipeline of projects and their sporadic nature

- A perceived lack of commitment to PPPs across all jurisdictions in Australia

- The size of the bid costs

An interesting point of difference was that several international participants considered that the requirement to demonstrate local experience was also a barrier. However, this view was not shared by the Federal Government.

These points are highly representative of the conclusions by many on both sides of the relationship and both sides of the debate. So, why do so few international contractors proceed beyond the Expressions of Interest (EOI) Stage? The answer may not lie in the 
consistency of views proposed by various stakeholders but in the inconsistency of views between government and internationals regarding barriers to entry as outlined above.

One project to successfully attract international contractors, see them progress through EOI and deliver compelling value for government was Legacy Way in Brisbane, Australia. However, the companies within the Joint Venture responsible for Legacy Way have been comparatively unsuccessful in proceeding beyond the EOI phase of subsequent projects. Given the significant similarities in size and complexity of Legacy Way and the projects being targeted by these contractors, this presents a confounding concern for government and international contractors. Has the courtship been a brief fling or is there potential for a fulfilling marriage?

This paper uses the authors' experience gained during the Legacy Way project as a case study and hypothesises why Legacy Way was effective in securing international contractors and perhaps why other contemporary projects may not be as successful - as this is clearly not the intent of the various public bodies involved in the letting of PPPs - the phrase 'inadvertent barriers to entry' is coined. In so doing, the authors make the assessment that significant barriers to entry do exist in the Australian construction industry but are cautious to highlight that they may be the consequence of cognitive biases. In the case of Legacy Way particular changes were made to the Expressions of Interest evaluation process and criteria to reduce the effect of any bias and it is the authors' belief that if these changes had not been made the eventual winner would not have qualified past the EOI stage.

The authors' intent is to highlight the frame of mind adopted on Legacy Way, and the resultant actions undertaken in shaping the procurement process (particularly the EOI phase) and contrast them with operating philosophies and processes of conventional projects. The inference is that by repeating some of the behaviour adopted by the client on Legacy Way, it is possible that the procurement results may be replicated in part i.e. inclusion of international project teams beyond the EOI phase in a fair and transparent process.

We pose practical solutions that government agencies may consider adopting when engaging international companies. The initiatives span the full procurement cycle from initial market sounding through to interactive RFP processes. The aim of the paper is not to comment on the postulate that international competition is desirable and in the interests of the Australian public and taxpayer.

\section{Background}

\section{Project Description}

Brisbane City Council has undertaken several major infrastructure projects since 2005. Two of these projects were constructed by 'new' international contractors and second tier contractors. The $\$ 300 \mathrm{~m}$ Go Between Bridge was delivered under an Alliance between Brisbane City Council, Bouygues Traveaus Publics, Seymour Whyte and MacMahon and the $\$ 1.7 b n$ Legacy Way is under construction by the Transcity Joint Venture (Acciona, Ghella, BMD).

Brisbane City Council's initiatives appear, on the surface, to be consistent with, and remarkably similar to, other government's seeking international interest. However, their results provide compelling evidence to investigate a little deeper.

Legacy Way is the fourth of five major projects that form Brisbane City Council's TransApex programme. TransApex comprises: 
- CLEM7 (formerly North South Bypass Tunnel) - currently in operation with RiverCity Motorway SPV as concessionaire

- Airport Link - currently under construction with BrisConnections SPV as concessionaire

- Go Between Bridge - currently in operation with Brisbane City Council as owner/operator

- Legacy way (formerly Northern Link) - currently under construction with Brisbane City Council as owner/operator

- East-West Link - currently forecast for delivery by 2026

\section{The Procurement Cycle}

The procurement of large infrastructure projects in Australia usually follows a six step process involving:

1. Market Sounding

2. Issue of Request for Expression of Interest (EOI)

3. Short listing from the EOl's received

4. Issue of a Request for Proposal (RFP) to the shortlisted EOI respondents

5. Evaluation of RFP responses

6. Negotiation leading to the award of contract

This paper deals largely with steps $1-3$ and is based on the experience developed by the Transaction Team during the procurement of Legacy Way (formally known as the Northern Link Project).

\section{Development of the Procurement Process}

The procurement phase for Legacy Way was conducted over 24 months from September 2008 to September 2010. It followed a typical project lifecycle with prefeasibility in 2004, a preliminary assessment in 2007 and detailed feasibility in 2007-8. The procurement phase included a first phase of market sounding and EOI, a second phase of market sounding and EOI and the Request for Proposals phase. During the procurement phase the operating environment was particularly dynamic. An understanding of the macro environment, the industry dynamics and resources required/available was highly powerful for guiding the project through its development.

The project was initially conceived as a PPP, but due to the Global Financial Crisis and the poor comparison of forecast traffic with actual traffic experienced on other similar projects it quickly became apparent that there was not sufficient interest in the market to enable a competitive PPP process to proceed. Council therefore decided to undertake international market sounding to reignite market appetite in the project.

The feedback from the international companies canvassed in this campaign brought Council's attention to the following:

1. Large international companies were interested in the Australian market

2. These companies were discouraged from proceeding with EOl's due to a continued list of failures

3. They regarded the Australian Market as "a closed shop" dominated by the Major Australian Construction Companies. They were particularly concerned about members of the same group being allowed to submit competing offers

4. There appeared to be a lack of transparency in the evaluation process thus making the reason for failure hard to determine 
5. These companies were successful both in their own countries and in a number of overseas countries and other than for point 3 were unable to explain their lack of success in the Australian market

6. None of the companies visited had the appetite for taking greenfield traffic risk

It soon became apparent that overseas companies whilst interested in the Project were not ready to commit the resources required to submit an EOI unless some or all of points 3,4 and 6 were adequately addressed.

\section{Demonstrating Intent}

Based on the above feedback Council was determined to demonstrate that Legacy Way would be different; principally that the Council project team had listened to concerns of the Internationals and that positive steps were taken to present Legacy Way as a new project and minimise the risk of another failed EOI. This point is critical. Council was in a do or die situation. Not all projects experience the heightened sensitivity to failure that focuses efforts on finding new solutions to old problems.

This intent was predominantly demonstrated through visible changes to the EOI process and evaluation criteria that were difficult for many project team members and advisors to accept.

\section{Changes to Council EOI Evaluation Criteria}

The review resulted in the modifications to evaluation criteria as shown in table 1 below:

\begin{tabular}{|c|c|c|c|}
\hline $\begin{array}{c}\text { Criteria Prior to } \\
\text { Review }\end{array}$ & Criteria Post Review & Risks In New Criteria & Mitigation Strategy \\
\hline $\begin{array}{l}\text { Experience of the } \\
\text { Brisbane Market } \\
\text { Required }\end{array}$ & $\begin{array}{l}\text { Proven experience in } \\
\text { working in an overseas } \\
\text { market with a similar } \\
\text { environment to Brisbane } \\
\text { required and } \\
\text { demonstration of } \\
\text { capability to successfully } \\
\text { complete projects in new } \\
\text { jurisdictions }\end{array}$ & $\begin{array}{l}\text { Overseas proponents } \\
\text { would not have } \\
\text { experience of specific } \\
\text { Australian requirement } \\
\text { in terms of I.R., safety } \\
\text { and environmental } \\
\text { requirements }\end{array}$ & $\begin{array}{l}\text { Strongly encourage any } \\
\text { overseas partner to obtain } \\
\text { an Australian partner with } \\
\text { good local knowledge }\end{array}$ \\
\hline $\begin{array}{l}\text { Full Teams needed to } \\
\text { be formed }\end{array}$ & $\begin{array}{l}\text { Full teams need not be } \\
\text { formed at the EOI stage. } \\
\text { Other members could be } \\
\text { added during the RFP } \\
\text { stage. }\end{array}$ & $\begin{array}{l}\text { Shortlisted proponents } \\
\text { may not be able to form } \\
\text { full bid teams in the } \\
\text { required time frame and } \\
\text { some key members of } \\
\text { the team may not be } \\
\text { acceptable to council. }\end{array}$ & $\begin{array}{l}\text { Identify key consortium } \\
\text { members and require their } \\
\text { identification at the EOI } \\
\text { stage. Require } \\
\text { unsuccessful EOI } \\
\text { Respondents to release } \\
\text { team members thus } \\
\text { making them available for } \\
\text { the RFP phase }\end{array}$ \\
\hline $\begin{array}{l}\text { Evaluation criteria } \\
\text { somewhat vague }\end{array}$ & $\begin{array}{l}\text { Dictionary type definitions } \\
\text { used to define evaluation } \\
\text { criteria requirements }\end{array}$ & $\begin{array}{l}\text { Difficulty in ensuring } \\
\text { definitions were accurate }\end{array}$ & $\begin{array}{l}\text { Continue review by senior } \\
\text { project staff }\end{array}$ \\
\hline $\begin{array}{l}\text { Evaluation weighting } \\
\text { not published }\end{array}$ & $\begin{array}{l}\text { Evaluation weighting } \\
\text { published in the EOI } \\
\text { request }\end{array}$ & $\begin{array}{l}\text { Resistance from team } \\
\text { members used to } \\
\text { subjective format }\end{array}$ & $\begin{array}{l}\text { Carry out in-house reviews } \\
\text { and ensure weightings } \\
\text { truly represented Councils } \\
\text { concerns }\end{array}$ \\
\hline $\begin{array}{l}\text { Lack of Understanding } \\
\text { of EOI requirements }\end{array}$ & $\begin{array}{l}\text { Interactive EOI phase } \\
\text { proposed to enable } \\
\text { clarification from bidders }\end{array}$ & Probity Concerns & $\begin{array}{l}\text { Plan briefings with probity } \\
\text { auditor and of course have } \\
\text { probity auditor present } \\
\text { during briefings }\end{array}$ \\
\hline
\end{tabular}

Table 1 Modifications to the EOI Criteria

Livesey, P and Bold, J (2013) 'Overcoming inadvertent barriers to entry in large infrastructure projects', Australasian Journal of Construction Economics and Building, 13 (1) 85-91 


\section{Recognising Cognitive Biases of the Client}

Cognitive biases were first popularised by Kahneman and Tversky in the 70s (Kahneman and Tversky 1972, Tversky and Kahneman 1973, Kahneman and Tversky 1977). Since then, a growing list of cognitive biases has been developed by numerous researchers of decision making and theory in fields such as cognitive science, social psychology and behavioural economics (Gilovich, Griffin et al. 2002, Kahneman and Frederick 2002). Of particular interest in this case is the rational and irrational routes to status quo bias and the interplay between status quo bias, loss aversion and omission bias.

Of critical importance in this discussion is the objective of the shortlisting process. At EOI stage, clients intend to decide, using incomplete information, which entities are most likely to provide the most compelling binding offer following the RFP phase. This establishes a decision making process that is complex with essentially incomplete information (committed bids are unknown) and thus introduces the need for 'intuitive' responses by advisors reporting on the submissions of each EOI respondent.

It could be argued that a rational path to status quo bias exists - that is, it is 'safer' to select known choices (in this case contractors with reputable records in Australia with whom advisors are familiar) because local contractors generally deliver acceptable results. However, this line of interrogation leads to maintaining the status quo and in the case of Legacy Way would have risked a failed process. More broadly, adopting this view fails to deliver on the outcomes sought by Infrastructure Australia - i.e. removing barriers "that might reduce the competitiveness of the PPP procurement process such as to prevent Governments from achieving best value for money (even if they still achieve value for money in an absolute sense)" (KPMG 2010)

Instead, irrational paths to status quo bias include loss aversion, and omission bias. We propose that when advisers are faced with making assessments about potential bidders they subconsciously emphasise the prospect of a loss (i.e. arriving at a decision that is unfamiliar, not the norm and results in a worse outcome than traditionally experienced). This results in assessments of potential bidders that would follow the function presented by Kahneman and Tversky's prospect theory (Kahneman and Tversky 1979). Australian and/or familiar Contractors, sub-contractors and personnel would sit in the right hand upper quadrant and unfamiliar Contractors in the lower left. These weightings are unintentional and occur prior to any formal scoring of participants and are therefore unlikely to be observed in the majority of projects.

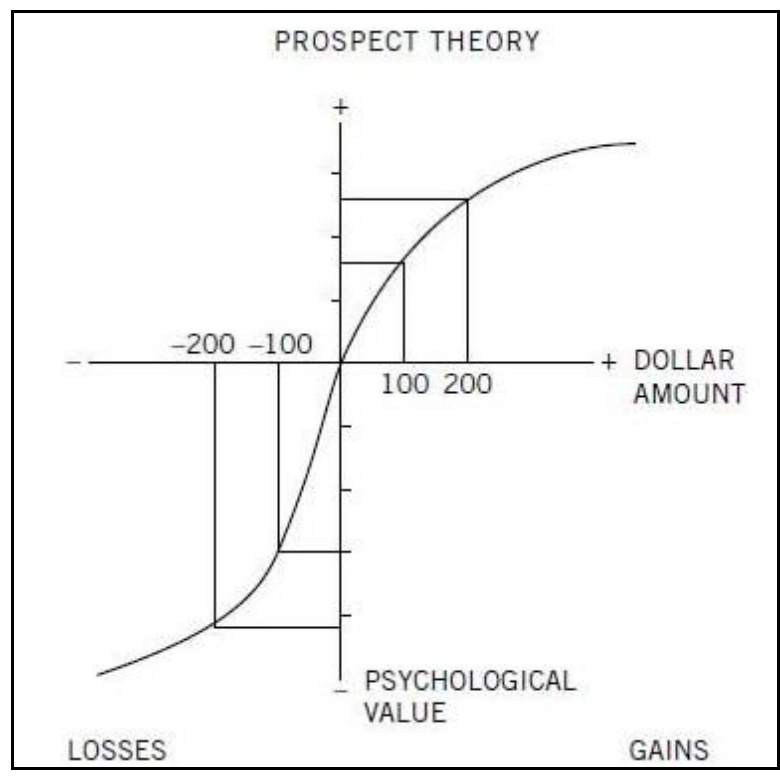

Figure 1 Prospect Theory

Livesey, P and Bold, J (2013) 'Overcoming inadvertent barriers to entry in large infrastructure projects', Australasian Journal of Construction Economics and Building, 13 (1) 85-91 
Legacy Way was somewhat unique due to the environmental conditions of the time in that the prospect of a failed process was acting against the status quo (i.e. the prospect of a loss through inaction meant changing behaviour was positively valued). Further, the project team was made up of individuals with less personal familiarity with local Contractors and through numerous market soundings became arguably equally familiar with international contractors thereby minimising (not eradicating) possible cognitive biases.

\section{The Evaluation Process}

A two stage evaluation process was developed:

Stage 1 Compliance: Requiring that the required information had been adequately submitted:

Stage 2 Comparative Assessment: In which those EOl's passing stage 1 were scored against the evaluation criteria.

Request for expression of interest were sent out in December 2009 and six responses, four of which were from overseers groups, were received in March 2010.

\section{The Result}

The RFP Process and Project Award

RFP's were issued to:

- Transcity (a consortium of Aciona, Ghella and BMD)

- Northern Direct (Bouygues and Laing O'Rourke)

- LBRJV (a consortium consisting of Leightons, Baulderstone and Razel)

After a detailed evaluation process the project was awarded to the TransCity joint venture for a bid price well below Brisbane City Council's budget and substantially below alternatives proposed by Contractors more familiar with the Australian environment. Needless to say, speculation was rife in industry regarding the likely performance of TransCity and Council. The final outcome for the project financially and technically is of interest to many in the industry.

\section{Current status}

Two years into the construction of Legacy Way, publicly available information on financial and technical progress is relatively limited. Anecdotal evidence points to a sound relationship between government and Contractor with positive comments regarding stakeholder management. Technically, recent tunnelling rates have resulted in setting a world record for $11 \mathrm{~m}$ TBMs with $48 \mathrm{~m}$ of advance in one week.

\section{Conclusion}

Using Legacy Way as a case study provides several insights:

- Inadvertent barriers to entry may help to explain why international contractors systematically fail to pass EOls

- Demonstrably changing the EOI process to herald the intent of the client may assist in increasing international contractor appetite (eschewing status quo for the sake of building trust)

- Maintaining internal focus on the objectives of EOI assessments, the relative incompleteness of information and hence complexity of the decision may highlight potential cognitive biases

- Gaining equal exposure to potential international and local bidders and structuring a project team with broad international experience may balance the cognitive biases 
- Environmental conditions may serve to exacerbate or counteract loss aversion of selecting unfamiliar contractors

- The RFP stage is where a more complete picture of each bidder's offer is presented but cognitive biases may still exist in complex decisions requiring subjective assessments

Being aware of and taking steps to mitigate potential cognitive bias may hold the key to nuptial bliss between International Contractors and the Australian Government. In our ongoing commitment to achieving best value for money on major infrastructure projects, can we afford to maintain the status quo?

\section{References}

Gilovich, T., et al. (2002) Heuristics and biases: The psychology of intuitive judgment, Cambridge University Press

Kahneman, D. and S. Frederick (2002) 'Representativeness revisited: Attribute substitution in intuitive judgment', Heuristics and biases: The psychology of intuitive judgment, 49-81

Kahneman, D. and A. Tversky (1972) 'Subjective probability: A judgment of representativeness', Cognitive psychology, 3 (3), 430-454

Kahneman, D. and A. Tversky (1977) Intuitive prediction: Biases and corrective procedures, DTIC Document

Kahneman, D. and A. Tversky (1979) 'Prospect theory: An analysis of decision under risk', Econometrica: Journal of the Econometric Society, 263-291

KPMG (2010) Advisory report for Infrastructure Australia

Tversky, A. and D. Kahneman (1973) 'Availability: A heuristic for judging frequency and probability', Cognitive psychology 5 (2), 207-232 